\title{
The Prevalence of Cryptosporidium Oocysts in Birds in Zaria, Nigeria
}

\author{
PWAVENO H. BAMAIYI*1, JARLATH U. UMOH ${ }^{1}$, PAUL A. ABDU² \& IDRIS A. \\ $\mathrm{LAWAL}^{3}$ \\ ${ }^{I}$ Department of Veterinary Public Health, Faculty of Veterinary Medicine, Ahmadu Bello University, \\ Zaria, Nigeria; ${ }^{2}$ Department of Veterinary Medicine and Surgery, Faculty of Veterinary Medicine, \\ Ahmadu Bello University, Zaria, Nigeria; ${ }^{3}$ Department of Veterinary Parasitology and Entomology, \\ Faculty of Veterinary Medicine, Ahmadu Bello University, Zaria, Nigeria
}

\begin{abstract}
A study was conducted to elucidate the prevalence of Cryptosporidium oocysts in birds in Zaria, Nigeria. A total of 890 faecal samples comprising 132, 305 and 453 from wild, local and exotic birds respectively from different parts of Zaria were examined using the formol-ether concentration technique with safranin-methylene blue stain and auramine phenol stain using light microscopy and fluorescent microscopy respectively. The total prevalence rate was $7.4 \%$. However, Samaru had the highest prevalence rate of $20.6 \%$ and Tudun Wada the lowest rate of $2.8 \%$. The difference in the prevalence rates between the different localities of Zaria was found to be statistically significant $(\mathrm{P}<0.001)$. Among the different birds sampled, local birds had the highest prevalence rate of $9.5 \%$ followed by exotic birds $6.6 \%$ and the wild ones with $5.3 \%$. The difference was not statistically significant $(\mathrm{P}>0.05)$. In Tudun Wada, where the different sexes were noted, there was no significant statistical difference $(\mathrm{P}>0.05)$ in the prevalence rate between male and female birds and none between the different species of wild birds sampled $(\mathrm{P}>0.05)$. This study confirms the presence of avian Cryptosporidium in Zaria, Nigeria and indicates that whereas location may influence infection, breed, sex and species of birds may not be significant factors in the epidemiology of the infection.
\end{abstract}

Keywords: Prevalence, Cryptosporidium, oocysts, birds, Nigeria

\section{INTRODUCTION}

Cryptosporidium is a zoonotic coccidian protozoan parasite that has gained significant attention in the last 25 years as a clinically important human and animal pathogen (Sevá et al. 2011; Sréter \& Varga 2000).

There are 3 main Cryptosporidia affecting birds namely Cryptosporidium baileyi, Cryptosporidium galli and Cryptosporidium meleagridis (Qi et al. 2011; Wang et al. 2011).

For many years Cryptosporidum was thought to be a rare opportunistic animal pathogen until the first case of human cryptosporidiosis was reported in 1976 involving a 3-year-old girl from rural Tennessee suffering from severe gastroenteritis for two weeks (Nime et al. 1976). Using electron microscopy of the intestinal mucosa C. parvum was implicated as the infectious species in man. In the 1980s, the significant association between cases of cryptosporidiosis and individuals with immuno-deficiency (e.g.

*Corresponding author: phbamaiyi@yahoo.com those with the acquired immuno-deficiency syndrome - AIDS) brought the parasite to lime light as a ubiquitous human pathogen (Guerrant 1997; Monis \& Thompson 2003). From the 1990 s to date the increasing population of immuno-compromised individuals and the various outbreaks of cryptosporidiosis through infection by waterborne and food borne Cryptosporidium oocysts, even in immuno-competent individuals, have placed even a greater emphasis on this pathogen (Guerrant 1997; Qi et al. 2011).

Unlike most intestinal pathogens Cryptosporidum can infect several different animal and human hosts, in fact infection has been reported in over 170 host species (Nagano et al. 2007; O’donoghue 1995; Sevá et al. 2011). Although human infection is mainly due to $C$. parvum, the two main species found in birds, $C$. baileyi and $C$. meleagridis, have also been reported to infect humans (Ditrich et al. 1991; Pedraza-Díaz et al. 2001; Plutzer \& Tomor 2009; Qi et al. 2011). 
Cryptosporidium parvum has also been found to retain its viability and infectivity after passing through the intestine of birds (Graczyk et al. 1996). Therapeutic remedies for this infection has not been very effective but the drug paromomycin has promising effects for treatment and prophylaxis (Johnson et al. 2000).

Previous workers have elucidated significant association between Cryptosporidium infection and age, season, land use and habitat and no association with sex of the bird (Ziegler et al. 2007). In a poultry house and on shared water sources, drinking water is an effective means of sharing the oocysts among birds and hence infecting a large number (Sréter \& Varga 2000). Qi et al. (2011) described the prevalence of 3 species ( $C$. baileyi, $C$. meleagridis and $C$. galli) and 2 genotypes (Cryptosporidium avian genotype III and Cryptosporidium avian genotype V) of Cryptosporidium from pet birds with an overall prevalence of $8.1 \%$ out of 434 faecal samples taken from 14 families of birds from different bird pet shops. In another study using 242 faecal samples from wild birds 16 (6.6\%) were positive for Cryptosporidium oocysts but factors associated with prevalence were not elucidated. The infection usually varies from one geographical location to another depending on many factors that may favour or limit the infection (Ryan 2010; Sréter \& Varga 2000).

In Nigeria, Some workers have reported Cryptosporidium spp. in calves (Ayinmode et al. 2010; Maikai et al. 2011) but there is paucity of literature on the status of Cryptosporidium infection in birds. The potential threats of Cryptosporidium species in birds to man and animals should not be underestimated. This study was therefore, conducted to determine the prevalence of Cryptosporidium oocysts in birds in Zaria and elucidate some factors associated with the infection.

\section{MATERIALS \& METHODS}

\section{Sample Collection}

A total of 890 faecal samples were collected from birds in Zaria $\left(11^{\circ} 4^{\prime} 0^{\prime \prime} \mathrm{N} / 7^{\circ} 42^{\prime} 0^{\prime \prime} \mathrm{E}\right)$, Nigeria (Travelmath 2011). The samples from
Samaru, Tudun Wada and Sabon Gari areas of Zaria were collected mainly from their various markets while the samples from Shika, Zaria were collected from the Poultry Farm of the National Animal Production Research Institute (NAPRI) Shika, Zaria. The rainy season was defined as April to September and the dry season as October to March. Wild birds were trapped into cages (with feed inside) within Samaru and Tudun Wada areas of Zaria, Nigeria. Faecal samples were either directly collected into universal bottles and $10 \%$ formol saline immediately added as a preservative before processing or they were collected using the disposable leather gloves and processed immediately on return to the laboratory.

\section{Processing of Samples}

About $1 \mathrm{~g}$ of the faecal sample (sometimes with intestinal contents) were homogenised in $10 \mathrm{ml}$ of $10 \%$ formol saline using a pestle and mortar or using an applicator stick in a universal bottle. This was sieved through gauze on a funnel into a centrifuge tube. $1 \mathrm{ml}$ of diethyl ether was then added to the filtrate to extract fat and minimize debris and the extract was centrifuged at 5,000 revolutions/minute for 10 minutes. The supernatant was decanted and a thin smear was made from thoroughly mixed sediment on a clean micro slide and air-dried (Baxby et al. 1984).

\section{Staining Techniques}

\section{Safranin-methylene blue staining technique}

The air-dried smear on a clean micro slide was fixed with $3 \%$ acid alcohol for $3-5$ minutes. The slide was then flooded with $1 \%$ aqueous safranin and heated from bottom with a spirit flame or bunsen flame for 1 minute. It was then rinsed gently in clean tap water and counterstained with $1 \%$ methylene blue for 1 minute. The methylene blue was thoroughly rinsed off with clean tap water. The slide was air-dried and examined under the microscope using the X 40 objective and oil immersion objective. The oocysts of Cryptosporidium appear as small spherical to round bright orange to reddish mass within a halo (Baxby et al. 1984). 


\section{Auramine phenol staining technique}

The air-dried positive faecal smears using the safranin-methylene blue staining technique on clean micro slides were fixed with methanol for 3 minutes and then exposed to formalin vapour at $37^{\circ} \mathrm{C}$ for 30 minutes. Slides were stained with auramine phenol (auramine $\mathrm{O}$, $0.03 \mathrm{~g}$, phenol $3 \mathrm{~g}$, distilled water $100 \mathrm{ml}$ ) for 10 minutes, washed in tap water, decolourised with $3 \%$ acid alcohol for 5 minutes, washed, counterstained with $0.1 \%$ potassium permanganate for 30 seconds, washed, air dried, and examined with a Leitz incident light fluorescence microscope. Specimens were screened at X 50 magnification and Cryptosporidium oocysts were clearly visible as yellowish discs against a dark background (Casemore et al. 1984).

\section{Identification}

\section{Identification Standard}

Faecal samples smears that were positive using the safranin-methylene blue staining technique and also positive with the auramine phenol staining technique were considered truly positive and recorded as the positive samples.

Positive slides of Cryptosporidium oocysts provided by Dr. Bruce Anderson of University of Idaho U.S.A. and Dr. Liisa Jokipii of Institutum Serobacteriologicum Universitatis, Helsinki served as control throughout the study.

\section{Statistical Analysis}

Data generated were analysed on the computer statistical package SigmaStat and Epi Info ${ }^{\mathrm{TM}}$ using Chi-square and Odds ratio analysis and differences expressed as significant at 95\% confidence level (Thrusfield 2005).

\section{RESULTS}

Table 1 indicates the prevalence of Cryptosporidium oocysts according to location. The highest frequency of detection was obtained in Samaru (20.6\%). The distribution of the frequency of detection by location was statistically significant $\left(\mathrm{X}^{2}=21.45, \mathrm{P}<0.05\right)$.

Local chickens had a higher rate of detection $(9.5 \%)$ than either exotic birds $(6.6 \%)$ or wild birds (5.3\%) (Table 2). However, the difference in the distribution of positive cases among the types of birds was not statistically significant $\left(\mathrm{X}^{2}=2.76, \mathrm{P}>0.05\right)$.

The infection was more common in broilers $(19.1 \%)$ than in cocks $(8.5 \%)$, layers $(3.9 \%)$ and breeders $(0.8 \%)$ (Table 3$)$. The distribution of infection rates in the different types of exotic chickens was statistically significant $\left(X^{2}=22.05, P<0.001\right)$.

Table 4 shows the prevalence of Cryptosporidium among the different species of wild birds sampled. The village weaver (Ploceus cucullatus) had the highest prevalence rate $(14.3 \%)$.

Table 5 indicates that the infection was more common in the local $(9.5 \%)$ than in the exotic birds $(6.6 \%)$ and was 1.5 times more likely to occur in the local than in the exotic birds although the difference in their prevalence rates was not statistically significant $(\mathrm{P}>0.05)$. The infection was also more common in the local birds as compared with the wild birds (5.3\%) and was 1.9 times more likely to occur in the local than in the wild birds (Table 6) but the difference in their prevalence rates was not statistically significant $(\mathrm{P}>0.05)$.

Table 1. The prevalence of Cryptostoridium oocysts according to location of local and exotic birds.

\begin{tabular}{lccc}
\hline Location & Sample size & Number positive & \% Positive \\
\hline Samaru & 97 & 20 & 20.6 \\
Sabon Gari & 102 & 6 & 5.9 \\
Tudun Wada & 106 & 3 & 2.8 \\
NAPRI - Shika & 453 & 30 & 6.6 \\
\hline Total & 758 & 59 & 7.8 \\
\hline $\mathrm{P}<0.001$ & $\mathrm{X}^{2}=21.453$ & &
\end{tabular}


Table 2. The prevalence of Cryptostoridium oocysts according to types of birds sampled.

\begin{tabular}{lccc}
\hline Birds & Sample size & Number positive & \% Positive \\
\hline Wild birds & 132 & 7 & 5.3 \\
Local chickens & 305 & 29 & 9.5 \\
Exotic chickens & 453 & 30 & 6.6 \\
\hline Total & 890 & 66 & 7.4 \\
\hline $\mathrm{P}=0.252$ & $\mathrm{X}^{2}=2.759$ & &
\end{tabular}

Table 3. The prevalence of Cryptostoridium oocysts according to the different types of exotic chicken sampled.

\begin{tabular}{lccc}
\hline Exotic chickens & Sample size & Number positive & \% Positive \\
\hline Layers & 127 & 5 & 3.9 \\
Breeders & 129 & 1 & 0.8 \\
Cocks & 129 & 11 & 8.5 \\
Broilers & 68 & 13 & 19.1 \\
\hline Total & 453 & 30 & 6.6 \\
\hline $\mathrm{P}<0.001$ & $\mathrm{X}^{2}=22.049$ & &
\end{tabular}

Table 4. The prevalence of Cryptostoridium oocysts among the different species of wild birds sampled.

\begin{tabular}{lccc}
\hline Species of birds & Sample size & Number positive & \% Positive \\
\hline Speckled pigeons (Columba guinea) & 41 & 1 & 2.4 \\
Laughing doves (Streptopelia senegalensis) & 37 & 2 & 5.4 \\
Mourning doves (Streptopelia decipiens) & 15 & 0 & 0 \\
Village weavers (Ploceus cucullatus) & 28 & 4 & 14.3 \\
Brown babblers (Turdoides plebejus) & 2 & 0 & 0 \\
Black crakes (Limnocorax flavirostra) & 3 & 0 & 0 \\
Red bishops (Euplectes orix) & 4 & 0 & 0 \\
Bush fowls (Francolinus bicalcaratus) & 2 & 0 & 0 \\
\hline Total & 132 & 7 & 5.3 \\
\hline P $>0.05$ & & &
\end{tabular}

Table 5. The prevalence of Cryptostoridium oocysts between the local and exotic chickens.

\begin{tabular}{lcccc}
\hline & Positive & Negative & Total & \% Positive \\
\hline Local & 29 & 276 & 305 & 9.5 \\
Exotic & 30 & 423 & 453 & 6.6 \\
\hline Total & 59 & 699 & 758 & 7.8 \\
\hline $\mathrm{P}=0.188$ & $\mathrm{X}^{2}=1.732$ & $\mathrm{OR}=1.48$ & &
\end{tabular}

Table 6. The prevalence of Cryptostoridium oocysts between the local and wild birds.

\begin{tabular}{lcccc}
\hline & Positive & Negative & Total & \% Positive \\
\hline Local & 29 & 276 & 305 & 9.5 \\
Wild & 7 & 125 & 132 & 5.3 \\
\hline Total & 36 & 401 & 437 & 8.2 \\
\hline $\mathrm{P}=0.201$ & $\mathrm{X}^{2}=1.635$ & $\mathrm{OR}=1.88$ & &
\end{tabular}

Comparing the exotic and wild birds (Table 7) the infection was more common in the exotic birds $(6.6 \%)$ than in the wild birds (5.3\%) and was 1.3 times more likely to occur in the exotic than in the wild birds although the difference between the prevalence rates was not statistically significant $(\mathrm{P}>0.05)$.

In Tudun Wada where the sex of the local birds was recorded there was no statistical 
significant difference $(\mathrm{P}>0.05)$ in the prevalence rates between them although the infection was 1.1 times more likely to occur in the female $(2.9 \%)$ than in the male $(2.8 \%)$ (Table 8).

The infection was more common in the dry season $(10.4 \%)$ than in the wet (rainy) season $(6.2 \%)$. The infection was 1.8 times more likely to occur in the dry season than in the wet season (Table 9) and the difference in the prevalence rates between the seasons was statistically significant $(\mathrm{P}<0.05)$.

\section{DISCUSSION}

The prevalence rate of Cryptosporidium oocysts in Samaru (20.6\%) as compared with other locations was higher as the prevalence of the infection varies with geographical locations and depends on favourable factors for the infection to thrive (Sréter \& Varga 2000).

The local birds showed a higher prevalence rate of Cryptosporidium oocysts than other birds. This should be expected considering the main faecal-oral route of transmission of the infection since local birds are restless, indiscriminate scavengers for food and water as they are allowed to mostly roam freely, they are more likely to come in contact with sporulated oocysts of the organism from different sources including man and livestock (Ryan 2010).

However, the difference in the prevalence rate of Cryptosporidium oocysts among the local, exotic and wild birds was not statistically significant since all of them can equally be infected and none have been shown to have a higher resistance or higher susceptibility than others (Sréter \& Varga 2000). Wild birds may seem more likely to contaminate water bodies with Cryptosporidium oocysts through aerial deposition of infected faeces. Many outbreaks of cryptosporidiosis have been associated with drinking water such as the one in Milwaukee in 1994 in which about 403,000 people were infected (Mackenzie et al. 1994). Therefore, the detection of Cryptosporidium oocysts in wild birds is very significant as many of them move from one water source to another and hence may contaminate them with viable oocysts.

Table 7. The prevalence of Cryptostoridium oocysts between the exotic and wild birds.

\begin{tabular}{lcccc}
\hline & Positive & Negative & Total & \% Positive \\
\hline Exotic & 30 & 423 & 453 & 6.6 \\
Wild & 7 & 125 & 132 & 5.3 \\
\hline Total & 37 & 548 & 585 & 6.3 \\
\hline $\mathrm{P}=0.730$ & $\mathrm{X}^{2}=0.119$ & $\mathrm{OR}=1.27$ & &
\end{tabular}

Table 8. The prevalence of Cryptostoridium oocysts in local chickens in Tudun Wada according to sex.

\begin{tabular}{lcccc}
\hline & Positive & Negative & Total & \% Positive \\
\hline Female & 1 & 33 & 34 & 2.9 \\
Male & 2 & 70 & 72 & 2.8 \\
\hline Total & 3 & 103 & 106 & 2.8 \\
\hline
\end{tabular}

$\mathrm{P}=1.000$ Fisher Exact test

Table 9. The prevalence of Cryptostoridium oocysts according to rainy and dry season.

\begin{tabular}{lcccc}
\hline & Positive & Negative & Total & \% Positive \\
\hline Dry season & 27 & 232 & 259 & 10.4 \\
Rainy season & 39 & 592 & 631 & 6.2 \\
\hline Total & 66 & 824 & 890 & 7.4 \\
\hline $\mathrm{P}=0.040$ & $\mathrm{X}^{2}=4.219$ & $\mathrm{OR}=1.77$ & &
\end{tabular}

KEY: $\quad \mathrm{P}=\mathrm{P}$ value

$\mathrm{X}^{2}=$ Chi-Square

$\mathrm{OD}=$ Odds ratio 
Broilers seem to have higher prevalence rates of Cryptosporidium spp. than the other birds (Sréter \& Varga 2000). Similar observation was also made in this study. There was a statistically significant difference in the prevalence rate of Cryptosporidium oocysts between layers, breeders, cocks and broilers. This may be due to the high metabolic rate of broilers as they are raised for meat coupled with their inherent genetic poor ability to resist infections, hence intestinal and other infections are very common in broiler chicken (Rao et al. 2009; Ryan 2010; Sréter \& Varga 2000). The deep litter system of raising the broilers also exposes them more to the infective oocysts in faeces and contaminated water. Breeders had the lowest prevalence rate of $0.8 \%$ as they may be more resistant to infection and are raised mostly in cages. The high prevalence rate of $6.6 \%$ in the exotic birds agrees with the findings of a worker who diagnosed Cryptosporidium in $6.8 \%$ of 1000 consecutive cases of chicken in Georgia diagnosed histologically (Goodwin \& Brown 1987).

Many of the wild birds sampled share similar feeding and drinking habits and hence may be equally exposed to many parasitic infections (Ziegler et al. 2007). The difference in the prevalence rates of Cryptosporidium infection in the wild birds examined was not statistically significant in spite of the variation in the prevalence rate of the village weaver (Ploceus cucullatus) as compared to the rest of the birds. The low number of samples taken from the different wild birds may account for the seeming wide variation between the prevalence rate of Cryptosporidium infection in the village weaver and other wild birds and may not allow conclusive statement to be made on the findings.

From large scale surveys by various workers in various animal species it was concluded that both sexes are equally susceptible to Cryptosporidium infection (Ryan 2010; Sréter \& Varga 2000; Wang et al. 2011). Findings from the present study seem to corroborate these observations. Sex is therefore not a very important factor for susceptibility to Cryptosporidium infection.
Cryptosporidium infection is prevalent all year round (Atwill et al. 1999), but our study indicates a significantly higher prevalence during the dry season. Oocysts of Cryptosporidium are also found in dust particles which are easily carried about from one place to another during the dry season especially harmattan, this prevalence rate may be expected. It is known that Cryptosporidium oocysts sporulate within the body and need no vectors or favourable conditions and can be carried about in the dust particles by the wind and other mechanism (Fayer et al. 2000; Plutzer \& Tomor 2009). Since the harmattan period is part of the dry season it may be that more oocysts were transported by this means leading to higher infection. The dry period may also mean going longer distances, especially, by the scavenging local birds to get feed and water which helps to spread the infection as they scavenge along. However, more work needs to be done for a longer period (at least 3 years) to determine if season is a factor in the prevalence of Cryptosporidium infection in birds.

\section{CONCLUSION}

This study has established the presence of Cryptosporidium infection in birds in Zaria. In view of the zoonotic potentials of the infection, the threats to human life should not be underestimated especially with the increasing number of pet birds and poultry and availability of susceptible groups such as newborn infants, the elderly, patients on immunosuppressive drugs, people infected with HIV, young animals, who are at a higher risk of infection. All breeds of birds are equally susceptible to Cryptosporidium infection. However, local birds and broilers seem more susceptible. Season and location may be significantly associated with Cryptosporidium infection.

\section{RECOMMENDATION}

More work needs to be done to establish the association of season with cryptosporidiosis. Cryptosporidium oocysts should be identified to species level especially using molecular techniques and to establish if C.parvum 
infection did occur in Nigerian birds under natural conditions apart from the $C$. baileyi and $C$. meleagridis infections. Experimental infection of our local birds especially, with $C$. parvum should be carried out to determine their role in the predominant human cryptosporidiosis which is mainly caused by C. parvum. In order to safeguard human life from cryptosporidiosis it is important to boil drinking water or use standard filtration techniques that are effective against the oocysts. Food should be properly cooked before consumption. Animals should be given water free of the oocysts. Animal farm houses should be managed with strict hygiene. Keeping birds in cages could minimize their chances of exposure to infected oocysts in the faeces.

\section{REFERENCES}

Atwill, E.R., Johnson, E.M., \& Pereira, M.G.C. (1999). Association of herds composition, stocking rate, and duration of calving season with faecal shedding of Cryptosporidium parvum oocysts in beef herds. Journal of the American Veterinary Medical Association, 215(12): 1833-1838.

Ayinmode, A.B., Olakunle, F.B., \& Xiao, L. (2010). Molecular characterization of Cryptosporidium spp. in native calves in Nigeria. Parasitology Research, 107: 10191021.

Baxby, D., Blundell, N., \& Hart, C.A. (1984). The development and performance of a simple, sensitive method for the detection of Cryptosporidium oocysts in faeces. Journal of Hygiene, 92: 317-323.

Casemore, D.P., Armstrong, M., Jackson, B., Nichols, G., \& Thom, B.T. (1984). Screening for Cryptosporidium in stools. Lancet, 1(8379): 734-735.

Ditrich, O., Palcovic, L., Sterba, J., Prokopic, J., Loudova, J., \& Giboda, M. (1991). The First finding of Cryptosporidium baileyi in man. Parasitology Research, 77: 44-47.

Fayer, R., Morgan, U., \& Upton, S.J. (2000). Epidemiology of Cryptosporidium: transmission, detection and identification. International Journal for Parasitology, 30: 1305-1322.
Goodwin, M.A. \& Brown, J. (1987). Histologic incidence and distribution of Cryptosporidium sp. infection in chickens. Journal of the American Veterinary Medical Association, 190: 1623.

Graczyk, T.K., Cranfield, M.R., Fayer, R., \& Anderson, S.M. (1996). Viability and infectivity of Cryptosporidium parvum oocysts are retained upon intestinal passage through a refractory avian host. Applied and Environmental Microbiology, 62(9): 32343237.

Guerrant, R.L. (1997). Cryptosporidiosis: An emerging, highly infectious threat. Emerging Infectious Diseases, 3(1): 51-56.

Johnson, E.H., Windsor, J.J., Muirhead, D.E., King, G.J., \& Al-Busaidy, R. (2000). Confirmation of the prophylactic value of paromomycin in a natural outbreak of caprine cryptosporidiosis. Veterinary Research Communications, 24(1): 63-67.

Mackenzie, W.R., Hoxie, N.J., Proctor, M.E., Gradus, M.S., Blair, K.A., \& Peterson, D.E. (1994). A massive outbreak of Cryptosporidium infection transmitted through the public water supply. New England Journal of Medicine, 331: 161-167.

Maikai, B.V., Umoh, J.U., Kwaga, J.K.P., Lawal, I.A., Maikai, V.A., Cama, V., \& Xiao, L. (2011). Molecular characterization of Cryptosporidium spp. in native breeds of cattle in Kaduna State, Nigeria. Veterinary Parasitology, 178(3-4): 241-245.

Monis, P.T. \& Thompson, R.C.A. (2003). Cryptosporidium and Giardia-Zoonoses: Fact or fiction? Infection, Genetics and Evolution, 3(4): 233-244.

Nagano, Y., Finn, M., Lowery, C., Murphy, T., Moriarty, J., Power, E., Toolan, D., O'Loughlin, A., Watabe, M., McCorry, K., Crothers, E., Dooley, J., Rao, J., Rooney, P., Millar, B., Matsuda, M., Elborn, J., \& Moore, J. (2007). Occurrence of Cryptosporidium parvum and bacterial pathogens in faecal material in the red fox (Vulpes vulpes) population. Veterinary Research Communications, 31(5): 559-564. 
Nime, F., Burck, J., Page, D., Holscher, M., \& Yardley, J. (1976). Acute enterocolitis in a human being infected with the protozoan Cryptosporidium. Gasteroenterology, 70: 592-598.

O'Donoghue, P.J. (1995). Cryptosporidium and cryptosporidiosis in man and animals. International Journal of Parasitology, 25: 139-195.

Pedraza-Díaz, S., Amar, C.F.L., McLauchlin, J., Nichols, G.L., Cotton, K.M., Godwin, P., Iversen, A.M., Milne, L., Mulla, J.R., Nye, K., Panigrahl, H., Venn, S.R., Wiggins, R., Williams, M., \& Youngs, E.R. (2001). Cryptosporidium meleagridis from humans: Molecular analysis and description of affected patients. Journal of Infection, 42(4): 243-250.

Plutzer, J. \& Tomor, B. (2009). The Role of Aquatic birds in the environmental dissemination of human pathogenic Giardia duodenalis cysts and Cryptosporidium oocysts in Hungary. Parasitology International, 58(3): 227-231.

Qi, M., Wang, R., Ning, C., Li, X., Zhang, L., Jian, F., Sun, Y., \& Xiao, L. (2011). Cryptosporidium spp. in pet birds: genetic diversity and potential public health significance. Experimental Parasitology, 128(4): 336-340. doi: 10.1016/j.exppara.2011.04.003.

Rao, J.R., Cherie Millar, B., \& Moore, J.E. (2009). Avian influenza, migratory birds and emerging zoonoses: unusual viral RNA, enteropathogens and Cryptosporidium in poultry litter. Bioscience Hypotheses, 2(6): 363-369.
Ryan, U. (2010). Cryptosporidium in birds, fish and amphibians. Experimental Parasitology, 124(1): 113-120. doi: 10.1016/j.exppara.2009.02.002.

Sevá, A.P., Funada, M.R., Richtzenhain, L., Guimarães, M.B., Souza, S.D.O., Allegretti, L., Sinhorini, J.A., Duarte, V.V., \& Soares, R.M. (2011). Genotyping of Cryptosporidium spp. from free-living wild birds from Brazil. Veterinary Parasitology, 175(1-2): 27-32.

Sréter, T. \& Varga, I. (2000). Cryptosporidiosis in birds - a review. Veterinary Parasitology, 87(4): 261-279.

Thrusfield, M. (2005). Veterinary epidemiology. Third edition. Oxford: Blackwell Publishing.

Travelmath. (2011). The latitude and longitude of Zaria, Nigeria. http://www.travelmath.com/city/Zaria,+Niger ia.

Wang, R., Qi, M., Jingjing, Z., Sun, D., Ning, C., Zhao, J., Zhang, L., \& Xiao, L. (2011). Prevalence of Cryptosporidium baileyi in ostriches (Struthio camelus) in Zhengzhou, China. Veterinary Parasitology, 175(1-2): 151-154.

Ziegler, P.E., Wade, S.E., Schaaf, S.L., Stern, D. A., Nadareski, C.A., \& Mohammed, H.O. (2007). Prevalence of Cryptosporidium species in wildlife populations within a watershed landscape in southeastern New York State. Veterinary Parasitology, 147(12): 176-184. 